\title{
Effects of sulfonylurea treatment on blood plasminogen activator inhibitor-1 levels in patients with type 2 diabetes mellitus: A network meta-analysis
}

Satoshi Ida*, Kazuya Murata and Ryutaro Kaneko

*Correspondence: bboy98762006@yahoo.co.jp

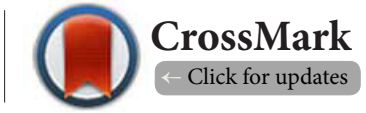

Department of Diabetes and Metabolism, Ise Red Cross Hospital, Mie, Japan.

\begin{abstract}
Background: To compare the effects ofthree types of sulfonylureas (glibenclamide, gliclazide, and glimepiride) on blood plasminogen activator inhibitor-1 levels in patients with type 2 diabetes mellitus, a network meta-analysis of randomized controlled trialswas performed.

Methods: A literature search using MEDLINE, the Cochrane Central Register of Controlled Trials, and ClinicalTrials.gov was conducted. Randomized controlled trialsin which the effects of sulfonylureas on blood plasminogen activator inhibitor-1 levels in patients with type 2 diabetes mellitus were evaluated were includes. Outcome assessment included standardized mean differences and $95 \%$ confidence intervals.

$\underline{\text { Results: }}$ Twelve randomized controlled trials (1,050 subjects) met the inclusion criteria and were included in the network meta-analysis. No significant difference was observedin blood plasminogen activator inhibitor-1 levels after using a placebo compared with those after using glibenclamide, gliclazide, and glimepiride. Blood plasminogen activator inhibitor-1levels were significantly lower after using gliclazide than after using glimepiride (standardized mean difference: $-0.52 ; 95 \%$ confidence interval: $-0.99 \%-0.44 \%$ ). However, no significant difference was observed in blood plasminogen activator inhibitor-1 levels after using glibenclamide compared with those after using gliclazide and glime piride.

Conclusions: Regarding the use of sulfonylureas for treating patients with type 2 diabetes mellitus, gliclazide may be preferable because of low blood plasminogen activator inhibitor-1 levels after its use. However, few studies have been published on the use of gliclazide, and the quality of these studies has been generally poor; thus, the results of this study should be interpreted with caution.
\end{abstract}

Keywords: Plasminogen, network meta-analysis, randomized controlled trial, type 2 diabetes mellitus

\section{Introduction}

Type 2 diabetes mellitus is associated with cardiovascular disease and cardiac death [1]. Therefore, in patients with type 2 diabetes mellitus, an important treatment goal is the prevention of cardiovascular disease. These patients are also prone to thrombosis, and plasminogen activator inhibitor-1 (PAI-1) levels, which determine fibrinolytic activity in the fibrinolytic system, are considered informative [2]. A previous studyhas reported that elevated blood PAI-1 levels are associated with arteriosclerosis and cardiovascular disease onset [3]. In patients with type 2 diabetes, presumably blood PAI- 1 levels are elevated [4], and factors controlling blood PAI-1 levels comprise theinsulin resistance, hyperglycemia, inflammatory cytokines, oxidative stress, and so on [5-7]. Apparently,these factors are not only induced by elevated blood PAI-1 levels, but alsoassociated with the promotion of the thrombus formation and myocardial fibrosis [5-7]. Probably, these mechanisms are involved in the correlation between elevated blood PAI-1 levels and cardiovascular disease.

Sulfonylureas, such as glibenclamide, gliclazide, and glimepiride, are pharmacotherapeutic agents that are widely used for treating type2 diabetes mellitus. These three sulfonylureas may 
Ida et al. Journal of Diabetes Research \& Clinical Metabolism 2018,

have different effects on the metabolic system. For example, gliclazide has been demonstrated to directly improve oxidative stress and inflammatory cytokine levels [8,9], whereas glimepiride reportedly promotes glucose uptake at the peripheral tissue level and improves insulin resistance [10]. In other words, presumably sulfonylureas probably lower blood PAI-1 levels by suppressing inflammatory cytokines, oxidative stress, and insulin resistance; however, we hypothesized that the effect of these three sulfonylureas on blood PAI-1 levels could differ depending on the drug (drug-effect). Previously, only a few randomized controlled trials (RCTs) have reportedthe effect of sulfonylurea administration on blood PAI-1 levels; thus, we believe that it is challengingto compare the difference in the effects of different drugs. Hence, this studyaimed to compare the effect of three different sulfonylureas on blood PAl-1 levels in patients with type 2 diabetes by using a network meta-analysis capable of indirectly estimating a difference in the drug-effect on the basis of RCTs.

\section{Methods \\ Study selection}

We conducted aliterature search using MEDLINE(https://www. ncbi.nlm.nih.gov/pubmed), the Cochrane Central Register of Controlled Trials(http://www.cochranelibrary.com/), and ClinicalTrials.gov(https://clinicaltrials.gov/) (accessedMay 1, 2017). The search strategy included "[gliclazide or glibenclamide or glimepiride or sulfonylurea] and [diabetes or NIDDM or non-insulin-dependent or type 2 diabetes mellitus] and [randomized controlled trial or controlled clinical trial or randomized or randomised or placebo or randomly]". Trials were eligible for inclusion if they compared sulfonylureas with placebos or oral antidiabetic drugs other than sulfonylureas, irrespective of diet and exercise therapies. Studies that were not RCTs, that featured animal experiments, that included patients with gestational diabetes, that contained insufficient data for analysis, or that were duplicates were excluded. Two authors (SI and RK) independently assessed whether each article satisfied the inclusion criteria. When the interpretations of the two authors were inconsistent, a third reviewer (KM) was consulted.

\section{Data extraction and quality assessment}

We created a data extraction form containing trial characteristics (key author's name, publication year, study location, sample size, patient's baseline information, basic treatment, and treatment duration). Regarding blood PAI-1 levels, we recorded mean values, standard deviation, standard error, or $95 \%$ confidence intervals $(\mathrm{Cls})$. In the event thata study compared a control group with two or more intervention groups, it was treated as two or more studies sharinga control group. Two authors (SI and RK) independently assessed the quality of the included trials. Quality was assessed using the Cochrane risk of bias tool [11]. Six domains (random sequence generation, allocation concealment, blinding of personnel and participants, blinding of outcome assessors, incomplete data, and selective reporting) were categorized as conferring a low, moderate, or high risk of bias.

\section{Statistical analysis}

The blood PAl-1 level was considered as a continuous variable and was recorded using different units in each study; therefore, we analyzed this variable using standardized mean differences (SMDs) and 95\% Cls. Therapeutic effect was considered as the difference among groups in the degree of change in blood PAI-1 levels before and after treatment. When only standard error or P-values were recorded, we calculated the standard deviation according to the method of Altman and Bland [12]. When standard deviation was not recorded, it was calculated from $95 \% \mathrm{Cls}, t$-values, or P-values [13].

First, as a direct comparison, we conducted standard pairwise meta-analysis using a random effects model. Next, as an indirect comparison, we performed a network meta-analysis. The random effects network meta-analysis was performed using the multivariate meta-analysis (mvmeta) routine in the statistical software STATA 13 (StataCorp LLC, College Station, TX, USA) [14,15], and the results of direct and indirect comparisons were integrated. Furthermore, we examined treatment hierarchy using the surface under the cumulative ranking curve (SUCRA). The SUCRA is an indicator ofthe efficacy of treatment for outcomes as a ranked percentage [16]. A SUCRA value closer to 100 indicates a more effective treatment, whereas a SUCRA value closer to 0 indicates a less effective treatment.

We examined inconsistency in the direct and indirect comparisons using the following methods. First, we examined the presence or absence of local inconsistency by comparing the therapeutic effect in the direct and indirect comparisons for all closed loops on the network (loop-specific test) [16]. Next, with regard to the presence or absence of global inconsistency, we examined inconsistency in the overall network by evaluating consistency in evidence obtained from different treatment designs (design-by-treatment interaction model) [17]. When the testing results for local and global inconsistencies yielded a P-value of $>0.05$, no inconsistency was deemed in the results of the direct and indirect comparisons.

\section{Results}

\section{Description of included studies}

Our literature search identified 4,021 articles, of which 12 RCTs ( 1,050 subjects) complied with the inclusion criteria and were therefore included in the meta-analysis (Figure 1) [18-29].

Table 1 shows the characteristics of the 12 trials, and Figure 2 shows the network map. The mean age of the participantswas 57.8 years; $47.7 \%$ participants were women. The mean diabetes duration was 5.7 years, and the mean trial duration was 23.3 weeks. Ten oral antidiabetic drugs (glibenclamide, gliclazide, glimepiride, metformin, nateglinide, pioglitazone, linagliptin, repaglinide, rosiglitazone, and troglitazone) and 

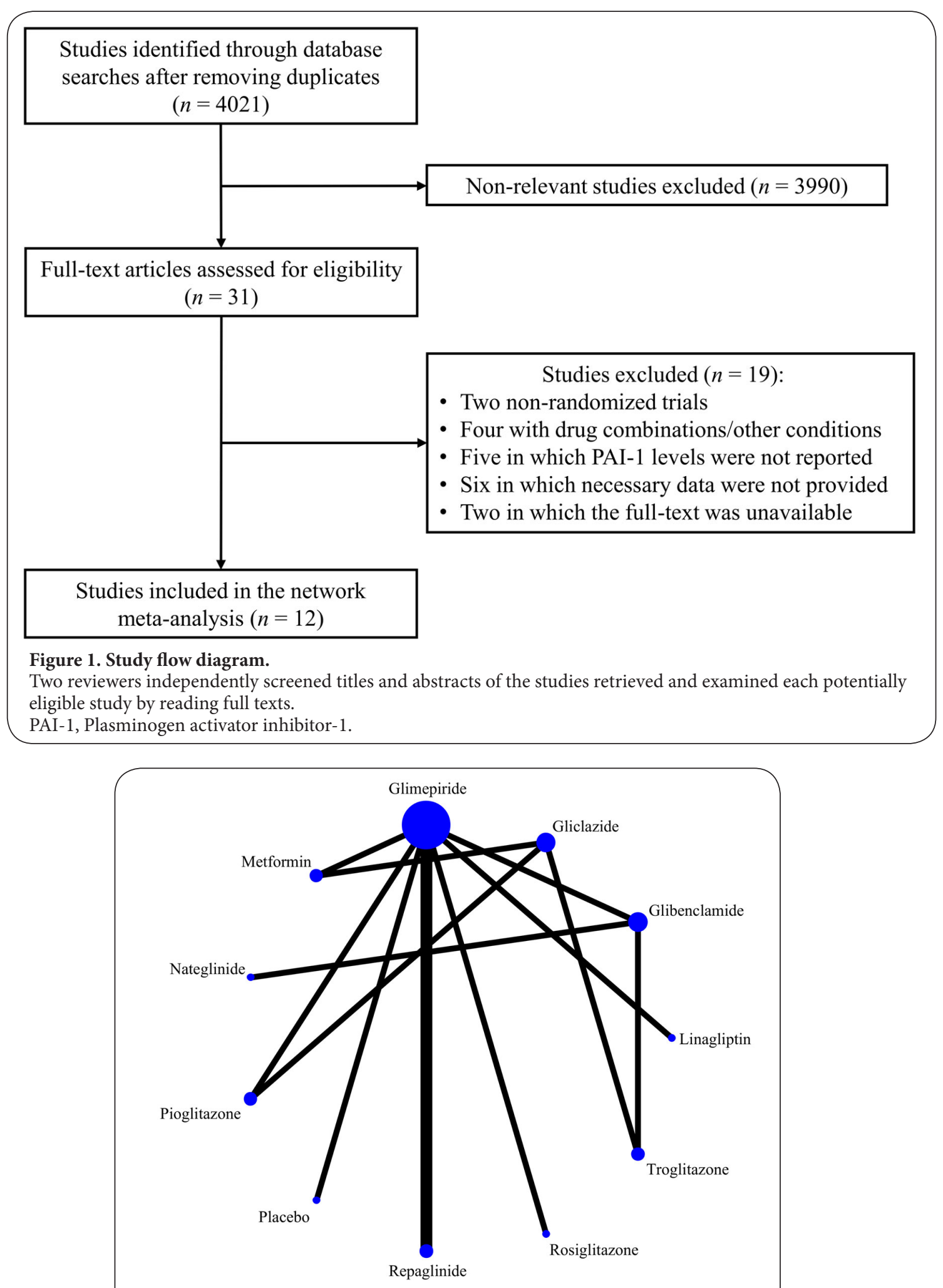

Figure 2. Network of clinical trials on sulfonylurea and other hypoglycemic drugs or placebos in patients with type 2 diabetes.

Lines connect the interventions that have been studied in head-to-head comparisons in the eligible randomized controlled trials (RCTs). The widths of the lines represent the total number of RCTs for each pairwise comparison. Node sizes are proportional to the number of randomized participants. 


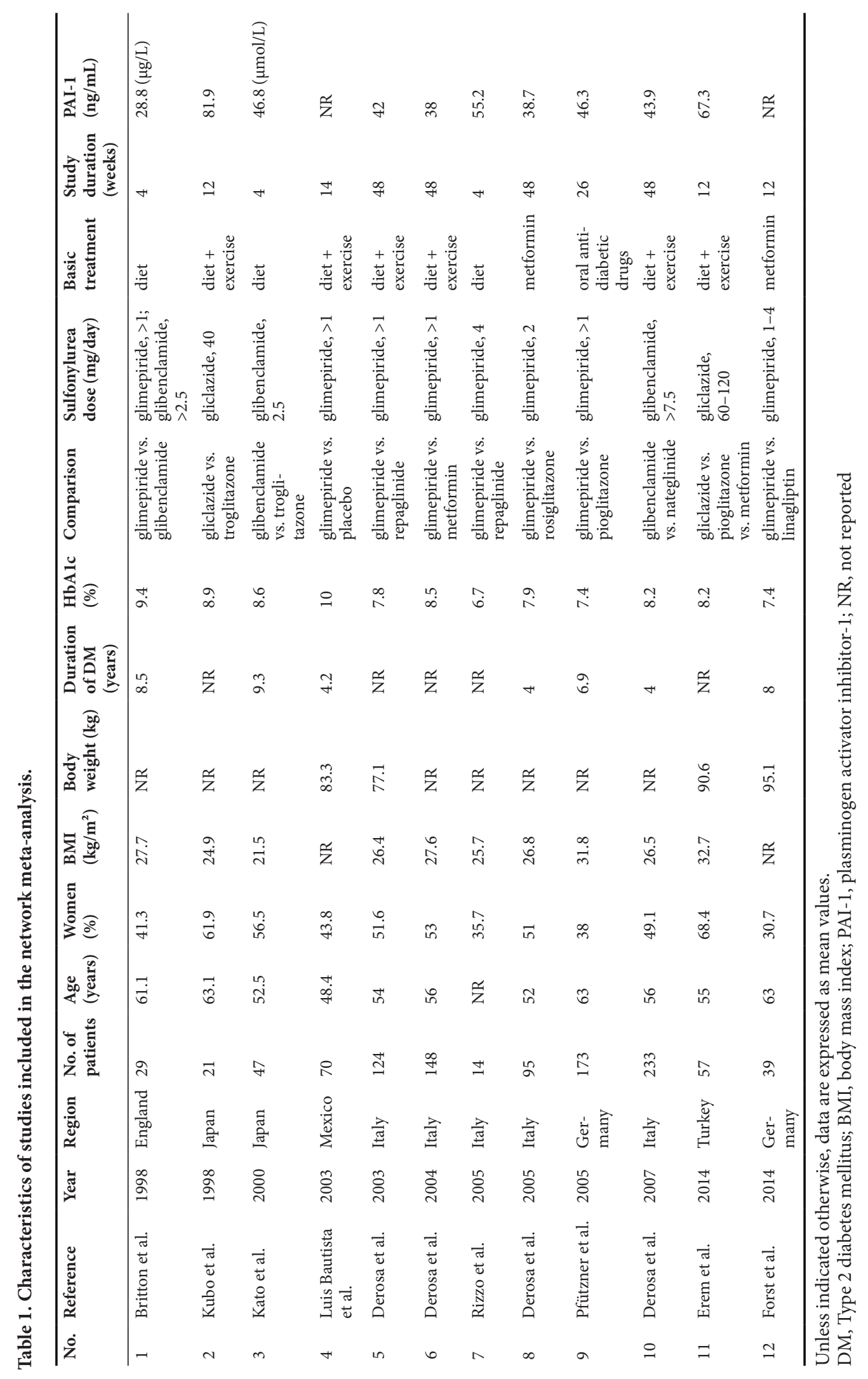


a placebo were included in the analysis.

\section{Assessment of potential bias}

The ratio of the presence of an appropriate description according to each domain was $25 \%$ (3/12) for random sequence generation, 25\% (3/12) for allocation concealment, 41.6\% (5/12) for blinding of participants and personnel, 8.3\% (1/12) for blinding of outcome assessors, $91.6 \%$ (11/12) for incomplete data, and $91.6 \%$ (11/12) for selective reporting. The quality of RCTs greatly varied. Generally, the overall risk of bias was high, and most biases arose from random sequence generation, allocation concealment, and blinding of outcome assessors.

\section{Direct pairwise meta-analysis}

Table 2 presents the results of the direct pairwise meta-analysis. Among glibenclamide, gliclazide, and glimepiride, the only drug that was compared with a placebo was glimepiride, and no significant difference in blood PAl-1 levels was evident among the drugs (SMD: $-0.03 ; 95 \% \mathrm{Cl}:-0.54 \%-0.47 \%$ ). Among the sulfonylureas, the effects of only glibenclamide and glimepiride on blood PAI-1 levels were compared, and no significant difference was found among the drugs(SMD: $-0.23 ; 95 \% \mathrm{Cl}$ : 0.75\%-0.29\%).

\section{Network meta-analysis}

Table 2 shows the results of the network meta-analysis. No significant difference was observed in blood PAl-1 levels after using glibenclamide, gliclazide, and glimepiride compared with those after using the placebo. Gliclazide achieved significantly lower blood PAI-1 levelsthan glimepiride (SMD: -0.52; $95 \% \mathrm{Cl}:-0.99 \%$ to $-0.44 \%)$. However, no significant difference was observed in blood PAl-1 levels after using glibenclamide and gliclazide compared with those after using glimepiride. In comparisons between gliclazide and other oral antidiabetic agents, blood PAI-1 levels were significantly lower after using gliclazide than after using metformin (SMD: -0.49 , 95\% $\mathrm{Cl}:-0.97$ to $-0.01 \%)$. Conversely, in comparisons between glibenclamideor glimepiride and other oral antidiabetic drugs, no significant difference or significantly high blood PAI-1 levels were observed.

Table 3 presents the results of the SUCRA analysis. The SUCRA values for glibenclamide, gliclazide, and glimepiride were $45.2 \%, 70.9 \%$, and $19.2 \%$, respectively, with the highest SUCRA value observed for gliclazide. Among the 10 oral antidiabetic agents, the highest SUCRA value was evident for troglitazone (99.5\%) and the lowest value was observed for repaglinide (18.1\%).

Inconsistency between direct and indirect evidence No local inconsistency was observed, except for oneclosed loop (quadratic loops; gliclazide-glimepiride-metforminpioglitazone). The loop-specific test revealed no significant difference and was consistent ( $\mathrm{P}=0.13)$. With regard to the presence or absence of global inconsistency, in the design- 
Ida et al. Journal of Diabetes Research \& Clinical Metabolism 2018,

Table 3. Ranking of the effect of sulfonylureas on blood plasminogen activator inhibitor-1 levels.

\begin{tabular}{lll}
\hline Treatment & SUCRA & Rank \\
\hline Placebo & 27.8 & 8 \\
Glibenclamide & 45.2 & 6 \\
Gliclazide & 70.9 & 4 \\
Glimepiride & 19.2 & 10 \\
Metformin & 23.7 & 9 \\
Nateglinide & 75.4 & 3 \\
Pioglitazone & 39.5 & 7 \\
Linagliptin & 79.9 & 2 \\
Repaglinide & 18.1 & 11 \\
Rosiglitazone & 50.8 & 5 \\
Troglitazone & 99.5 & 1 \\
\hline
\end{tabular}

SUCRA, surface under the cumulative ranking curve.

by-treatment interaction model, no significant inconsistency was observed between the direct and indirect comparisons $(\mathrm{P}=0.316)$.

\section{Discussion}

PAI-1 is a glycoprotein produced by vascular endothelial cells and enlarged adipocytes [30]. The fibrinolytic system is regulated by the balance between levels of PAI- 1 and tissue plasminogen activator, which is a protein that converts plasminogen into plasmin. In particular, PAI-1 contributes to the determination ofoverall fibrinolytic activity [3] Reportedly, patients with type 2 diabetes mellitus have elevated blood PAl-1 levels and are prone to thrombosis; therefore, a relationship exists between elevated PAI-1 levels, arteriosclerosis, and cardiovascular disease onset [3]. Elevated blood PAI-1levels are caused by tumor necrosis factor-a (TNF-a), oxidative stress, and low-density lipoprotein-type hyperlipoproteinemia andare correlated with insulin resistance, triacylglycerol levels, and very low-density lipoprotein levels [2,5-7]. Thecontrol of these factors is thought to play an important rolein the maintenance of low blood PAI-1 levels.

Presently, sulfonylureas available for routine medical practice include glibenclamide, gliclazide, and glimepiride. When sulfonylureas bind to adenosine triphosphate-sensitive $\mathrm{K}^{+}$channels found in the pancreatic $\beta$-cell membrane, they depolarizeit, leading to the opening of voltage-dependent $\mathrm{Ca}^{2+}$ channels. This increases the intracellular $\mathrm{Ca}^{2+}$ concentration viaextra cellular $\mathrm{Ca}^{2+}$ influx and causes insulin secretion [31]. Reportedly, sulfonylureas exhibit hypoglycemic effects through the potent stimulation of insulin secretion and extra pancreatic effects. Gliclazideexhibits a potent antioxidant effect through the azabicyclo-octyl ring in its structure. Lowering oxidative stress improves intravascular function and has an anti-arteriosclerotic effect [9] Glimepiride promotes glucose uptake in peripheral tissues by promoting adiponectin production and improves insulin resistance [10]. However, few reports have examined the extra pancreatic effects of glibenclamide. Despite the similarities between these sulfonylureas, they have different extra pancreatic effects and may have different effects on cardiovascular disease. However, their effects on cardiovascular disease remain unclear [32].

Because glibenclamide, gliclazide, and glimepiride have different extra pancreaticeffects, we hypothesized that their effects on blood PAI-1 levels would differ. We then investigated these differences using the network meta-analysis method. Our results revealed that gliclazide achieved significantly lower PAI-1 levels than glimepiride. Gliclazide exerts an oxidative stress-lowering effect, which is considered to be stronger than that of glibenclamideor glimepiride [33]. Furthermore, gliclazide therapy reportedly lowers TNF- $a$ and increases adiponectin levels [8]. Reduced TNF- $a$ and elevated adiponectin levels correlate with improved insulin resistance, which is thought to be associated with low blood PAI-1 levels $[34,35]$. Furthermore, glibenclamide and glimepiride carry a higher risk of hypoglycemia thangliclazide [36]. Low blood glucose levels increase blood PAI-1 levels [37], which may beanother reason why blood PAl-1 levels are lower after using gliclazide than after using glimepiride. However, in this study, we did not observe that blood PAI-1 levels were lowered more significantly by gliclazide than by the placebo. As a whole, the observation periods of the RCT included in our present study were short, with substantial discrepancy in patient background between each study. Further examination is warranted for ascertaining whether gliclazide exerts a blood PAI-1-lowering action, considering these problems, and with larger sample size.

In contrast, blood PAI-1 levels were significantly lower after using gliclazide than after using metformin. Reportedly, metformin lowers blood PAI-1 levels, which is thought to be associated with improvement in insulin resistance [38]. However, in reports on the ability of metformin to lower blood PAI-1 levels,observation periods varied from short to long $[38,39]$. Few reports have directly compared the effects of gliclazide and metformin on blood pAl-1 levels, and we believethat this issue requires further examination in the future. In the present study, of the agents examined, rosiglitazone achieved the greatest reduction in blood PAI- 1 levels. Thiazolidine derivatives, including rosiglitazone, act on the nuclear receptor peroxisome proliferator-activated receptor- $\psi$ in target organs, such as the skeletal muscles and liver,to improve insulin resistance. Furthermore, thiazolidine derivatives exhibit hypoglycemic effects by increasing adiponectin levels and improving insulin resistance in peripheral tissues. However, the use of rosiglitazone hasbeen discontinued, and it cannot be used in routine medical practice at present.

Although it remains unclear whether the administration of sulfonylureas impedes cardiovascular disease onset, which is the endpoint [32], the outcomes of the present study, i.e., blood PAI-1 levels, could serve as a surrogate marker for cardiovascular disease onset [3]. In the present study, glib- 
enclamide, gliclazide, and glimepiride were compared with the placebo, and no significant decrease in blood PAI-1 levels was observed after using the agents. However, on comparing the three agents, blood PAl-1 levels were significantly lower after using gliclazide than after using glimepiride. Aprior study reported that gliclazide administration to patients with type 2 diabetes reduced the rate of cardiovascular deaths [40]. From the perspective of blood PAI-1 levels, when using sulfonylureas in patients with type 2 diabetes mellitus, we believe that the use of gliclazidemay bepreferable.

To our knowledge, this is the first study to examine the effects of sulfonylureas on blood PAI-1 levels using network meta-analysis. Because trials with direct comparisons (head-tohead clinical trials) of drug effects are limited, the differences in drug effects to be evaluated are often unclear. Network meta-analysis enables differences in drug effects to be estimated on the basis of trials with direct comparisons and is a method that enables the most effective drugs to be ranked. In the RCTs included in the present study, direct comparison was performed only for glibenclamide and glimepiride. Indirect comparison by network meta-analysis enabled differences in the effects of the three agents examined.

This study has several limitations. First, we included relatively few RCTs, which may have resulted in weak statistical power. Furthermore, we included a few RCTs and could not perform subgroup analyses according to the age and the presence or absence of obesity, thereby restricting us from conducting a detailed analysis. Second, we cannot exclude the possibility that the literature in databases that we did not search could have affected our results. Third, there were largevariations between RCTs included in this study in terms of the observation period and drug doses used. Accordingly, caution should be exercised when interpreting and generalizing our results. Fourth, while we compared the effect of sulfonylureas on blood PAI-1 levels, we could notelucidate the underlying mechanism (such as whether an improvement in the insulin resistance and oxidative stress were involved). Last, the quality of included RCTs was generally poor, which casts doubt on the validity of our results.

\section{Conclusions}

We examined differences in the effects of glibenclamide, gliclazide, and glimepiride on blood PAI-1 levels. Our results revealed that blood PAI-1 levels were not significantly lower after using these agents than after using theplacebo. However, blood PAI-1 levels were significantly lower after using gliclazide than after using glimepiride. From the perspective of blood PAI-1 levels, when using sulfonylureas in patients with type 2 diabetes mellitus, we believe that the use of gliclazide is preferable. However, few studies were included in the present analysis, and their quality was generally poor; therefore, we feel that caution should be exercised when interpreting our results. Further analyses should be performed that take into account the limitations of our study to determine the effects of sulfonylureas on serum PAI-1 levelsin patients with type 2 diabetes mellitus.

\section{Competing interests}

The authors declare that they have no competing interests.

Authors' contributions

\begin{tabular}{|l|c|c|c|}
\hline Authors' contributions & SI & KM & RK \\
\hline Research concept and design & $\checkmark$ & $\checkmark$ & $\checkmark$ \\
\hline Collection and/or assembly of data & $\checkmark$ & $\checkmark$ & $\checkmark$ \\
\hline Data analysis and interpretation & $\checkmark$ & $\checkmark$ & $\checkmark$ \\
\hline Writing the article & $\checkmark$ & $\checkmark$ & $\checkmark$ \\
\hline Critical revision of the article & $\checkmark$ & $\checkmark$ & $\checkmark$ \\
\hline Final approval of article & $\checkmark$ & $\checkmark$ & $\checkmark$ \\
\hline Statistical analysis & $\checkmark$ & $\checkmark$ & $\checkmark$ \\
\hline
\end{tabular}

Acknowledgments and Funding

The authors would like to thank the staff members of the Department of Metabolic Diseases at the Ise Red Cross Hospital, Ise, Japan, for their cooperation in this study. This study received no funding.

\section{Publication history}

Editor: Geoffrey Burnstock, University College London, UK. Received: 02-Feb-2018 Final Revised: 27-April-2018

Accepted: 01-May-2018 Published: 12-May-2018

\section{References}

1. Mannucci E, Monami M, Lamanna C, Gori F and Marchionni N. Prevention of cardiovascular disease through glycemic control in type 2 diabetes: a meta-analysis of randomized clinical trials. Nutr Metab Cardiovasc Dis. 2009; 19:604-12. I Article I PubMed

2. Hoekstra T, Geleijnse JM, Schouten EG and Kluft C. Plasminogen activator inhibitor-type 1: its plasma determinants and relation with cardiovascular risk. Thromb Haemost. 2004; 91:861-72. | Article | PubMed

3. Erem C, Hacihasanoglu A, Celik S, Ovali E, Ersoz HO, Ukinc K, Deger O and Telatar M. Coagulation and fibrinolysis parameters in type $\mathbf{2}$ diabetic patients with and without diabetic vascular complications. Med Princ Pract. 2005; 14:22-30. I Article I PubMed

4. Eliasson M, Asplund K, Evrin PE, Lindahl B and Lundblad D. Hyperinsulinemia predicts low tissue plasminogen activator activity in a healthy population: the Northern Sweden MONICA Study. Metabolism. 1994; 43:1579-86. | Article I PubMed

5. Ghosh AK and Vaughan DE. PAI-1 in tissue fibrosis. J Cell Physiol. 2012; 227:493-507. | Article | PubMed Abstract | PubMed FullText

6. Rohla M and Weiss TW. Metabolic syndrome, inflammation and atherothrombosis. Hamostaseologie. 2013; 33:283-94. | Article | PubMed

7. D’Elia JA, Bayliss G, Gleason RE and Weinrauch LA. Cardiovascular-renal complications and the possible role of plasminogen activator inhibitor: a review. Clin Kidney J. 2016; 9:705-12. | Article | PubMed Abstract | PubMed FullText

8. Drzewoski J and Zurawska-Klis M. Effect of gliclazide modified release on adiponectin, interleukin-6, and tumor necrosis factor-alpha plasma levels in individuals with type 2 diabetes mellitus. Curr Med Res Opin. 2006; 22:1921-6. I Article I PubMed

9. Jennings PE. Vascular benefits of gliclazide beyond glycemic control. Metabolism. 2000; 49:17-20. | Article | PubMed

10. Tsunekawa T, Hayashi T, Suzuki Y, Matsui-Hirai H, Kano H, Fukatsu A, Nomura N, Miyazaki A and Iguchi A. Plasma adiponectin plays an important role in improving insulin resistance with glimepiride in elderly type 2 diabetic subjects. Diabetes Care. 2003; 26:285-9. | Article I PubMed 
11. Simmonds MC, Higgins JP, Stewart LA, Tierney JF, Clarke MJ and Thompson SG. Meta-analysis of individual patient data from randomized trials: a review of methods used in practice. Clin Trials. 2005; 2:209-17. | Article | PubMed

12. Altman DG and Bland JM. Detecting skewness from summary information. BMJ. 1996; 313:1200. | Article | PubMed Abstract | PubMed FullText

13. Higgins JPT and Green S. Cochrane Handbook for Systematic Reviews of Interventions Version 5.1.0. The Cochrane Collaboration. 2011. | Website

14. Mavridis D and Salanti G. A practical introduction to multivariate metaanalysis. Stat Methods Med Res. 2013; 22:133-58. | Article | PubMed

15. Jackson D, White IR and Riley RD. A matrix-based method of moments for fitting the multivariate random effects model for meta-analysis and meta-regression. Biom J. 2013; 55:231-45. | Article | PubMed Abstract | PubMed FullText

16. Chaimani A, Higgins JP, Mavridis D, Spyridonos P and Salanti G. Graphical tools for network meta-analysis in STATA. PLoS One. 2013; 8:e76654. | Article | PubMed Abstract | PubMed FullText

17. Jackson $D$, Boddington $P$ and White IR. The design-by-treatment interaction model: a unifying framework for modelling loop inconsistency in network meta-analysis. Res Synth Methods. 2016; 7:329-32. | Article | PubMed Abstract | PubMed FullText

18. Britton ME, Denver AE, Mohamed-Ali V and Yudkin JS. Effects of Glimepiride vs Glibenclamide on Ischaemic Heart Disease Risk Factors and Glycaemic Control in Patients with Type 2 Diabetes Mellitus. Clin Drug Investig. 1998; 16:303-17. I PubMed

19. Kubo K. Effects of troglitazone on coagulation-fibrinolysis abnormalities in patients with type II diabetes mellitus. Curr. Ther. Res. Clin. Exp. 1998; 59:537-544.

20. Kato K, Yamada D, Midorikawa S, Sato W and Watanabe T. Improvement by the insulin-sensitizing agent, troglitazone, of abnormal fibrinolysis in type 2 diabetes mellitus. Metabolism. 2000; 49:662-5. | Article | PubMed

21. Luis Bautista J, Bugos C, Dirnberger G and Atherton T. Efficacy and safety profile of glimepiride in Mexican American Patients with type 2 diabetes mellitus: a randomized, placebo-controlled study. Clin Ther. 2003; 25:194-209. | Article | PubMed

22. Derosa G, Mugellini A, Ciccarelli L, Crescenzi G and Fogari R. Comparison between repaglinide and glimepiride in patients with type 2 diabetes mellitus: a one-year, randomized, double-blind assessment of metabolic parameters and cardiovascular risk factors. Clin Ther. 2003; 25:472-84. | Article | PubMed

23. Derosa G, Franzetti I, Gadaleta G, Ciccarelli L and Fogari R. Metabolic variations with oral antidiabetic drugs in patients with Type 2 diabetes: comparison between glimepiride and metformin. Diabetes Nutr Metab. 2004; 17:143-50. | PubMed

24. Rizzo MR, Barbieri M, Grella R, Passariello N and Paolisso G. Repaglinide has more beneficial effect on cardiovascular risk factors than glimepiride: data from meal-test study. Diabetes Metab. 2005; 31:25560. | Article | PubMed

25. Derosa G, Gaddi AV, Piccinni MN, Ciccarelli L, Salvadeo S, Peros E, Ghelfi $M$, Ferrari I and Cicero AF. Antithrombotic effects of rosiglitazonemetformin versus glimepiride-metformin combination therapy in patients with type 2 diabetes mellitus and metabolic syndrome. Pharmacotherapy. 2005; 25:637-45. | PubMed

26. Pfutzner A, Marx N, Lubben G, Langenfeld M, Walcher D, Konrad T and Forst T. Improvement of cardiovascular risk markers by pioglitazone is independent from glycemic control: results from the pioneer study. $J$ Am Coll Cardiol. 2005; 45:1925-31. | Article | PubMed

27. Derosa G, D'Angelo A, Fogari E, Salvadeo S, Gravina A, Ferrari I and Cicero AF. Effects of nateglinide and glibenclamide on prothrombotic factors in naive type 2 diabetic patients treated with metformin: a 1-year, doubleblind, randomized clinical trial. Intern Med. 2007; 46:1837-46. | Article I PubMed

28. Erem C, Ozbas HM, Nuhoglu I, Deger O, Civan N and Ersoz HO.
Comparison of effects of gliclazide, metformin and pioglitazone monotherapies on glycemic control and cardiovascular risk factors in patients with newly diagnosed uncontrolled type 2 diabetes mellitus. Exp Clin Endocrinol Diabetes. 2014; 122:295-302. | Article I PubMed

29. Forst T, Anastassiadis E, Diessel S, Loffler A and Pfutzner A. Effect of linagliptin compared with glimepiride on postprandial glucose metabolism, islet cell function and vascular function parameters in patients with type 2 diabetes mellitus receiving ongoing metformin treatment. Diabetes Metab Res Rev. 2014; 30:582-9. | Article | PubMed

30. Cao H. Adipocytokines in obesity and metabolic disease. J Endocrinol. 2014; 220:T47-59. | Article | PubMed Abstract | PubMed FullText

31. Sturgess NC, Ashford ML, Cook DL and Hales CN. The sulphonylurea receptor may be an ATP-sensitive potassium channel. Lancet. 1985; 2:474-5. | Article | PubMed

32. Phung OJ, Schwartzman E, Allen RW, Engel SS and Rajpathak SN. Sulphonylureas and risk of cardiovascular disease: systematic review and meta-analysis. Diabet Med. 2013; 30:1160-71. | Article | PubMed

33. O'Brien RC, Luo $\mathrm{M}$, Balazs $\mathrm{N}$ and Mercuri J. In vitro and in vivo antioxidant properties of gliclazide. J Diabetes Complications. 2000; 14:201-6. | Article | PubMed

34. Lyon $\mathrm{CJ}$ and Hsueh WA. Effect of plasminogen activator inhibitor-1 in diabetes mellitus and cardiovascular disease. Am J Med. 2003; 115 Suppl 8A:62S-68S. | Article | PubMed

35. Kobayashi J, Kusunoki M, Murase Y, Kawashiri M, Higashikata T, Miwa K, Katsuda S, Takata M, Asano A, Nohara A, Inazu A and Mabuchi H. Relationship of lipoprotein lipase and hepatic triacylglycerol lipase activity to serum adiponectin levels in Japanese hyperlipidemic men. Horm Metab Res. 2005; 37:505-9. | Article | PubMed

36. Landman GW, de Bock GH, van Hateren KJ, van Dijk PR, Groenier KH, Gans RO, Houweling ST, Bilo HJ and Kleefstra N. Safety and efficacy of gliclazide as treatment for type $\mathbf{2}$ diabetes: a systematic review and meta-analysis of randomized trials. PLoS One. 2014; 9:e82880. | Article | PubMed Abstract | PubMed FullText

37. Joy NG, Mikeladze M, Younk LM, Tate DB and Davis SN. Effects of equivalent sympathetic activation during hypoglycemia on endothelia function and pro-atherothrombotic balance in healthy individuals and obese standard treated type 2 diabetes. Metabolism. 2016; 65:16951705. | Article | PubMed Abstract | PubMed FullText

38. de Jager J, Kooy A, Schalkwijk C, van der Kolk J, Lehert P, Bets D, Wulffele $M G$, Donker AJ and Stehouwer CD. Long-term effects of metformin on endothelial function in type 2 diabetes: a randomized controlled trial. J Intern Med. 2014; 275:59-70. | Article | PubMed

39. Eriksson A, Attvall S, Bonnier M, Eriksson JW, Rosander B and Karlsson FA. Short-term effects of metformin in type 2 diabetes. Diabetes Obes Metab. 2007; 9:483-9. | Article | PubMed

40. Schramm TK, Gislason GH, Vaag A, Rasmussen JN, Folke F, Hansen ML, Fosbol EL, Kober L, Norgaard ML, Madsen M, Hansen PR and TorpPedersen C. Mortality and cardiovascular risk associated with different insulin secretagogues compared with metformin in type 2 diabetes, with or without a previous myocardial infarction: a nationwide study. Eur Heart J. 2011; 32:1900-8. | Article | PubMed

\section{Citation:}

Ida S, Murata K and Kaneko R. Effects of sulfonylurea treatment on blood plasminogen activator inhibitor-1 levels in patients with type 2 diabetes mellitus: A network meta-analysis. J Diab Res Clin Met. 2018; 7:1. http://dx.doi.org/10.7243/2050-0866-7-1 